\title{
Harmonizing expression of measurement results in wine analysis: Best practices when testing and reporting sugar in wine
}

\author{
E. Wilkes ${ }^{1}$, P. Huckaba ${ }^{2}$, and G. Hodson ${ }^{3}$ \\ ${ }^{1}$ Australian Wine Research Institute, Hartley Grove, Urrbrae SA 5064, Australia \\ ${ }^{2}$ Bronco Wine Company, 6342 Bystrum Road, Ceres CA 95307, USA \\ ${ }^{3}$ FIVS, 18 rue d'Aguesseau, 75008 Paris, France
}

\begin{abstract}
This technical brief addresses using appropriate methodology and uniform terminology to ensure consistency in measurement and interpretation of wine components described as sugars, when required in wine trade. Different analytical approaches when testing for sugar in wine, variation in reporting units, and nonuniform interpretation of sugar terminology are known to create unnecessary barriers in wine trade. This brief proposes a unified system of reporting sugar in wine that is grounded in scientific and practical knowledge to reduce potential trade barriers. The following are suggested best practices when testing and reporting sugar in wine: clarify the meaning of the abbreviation "RS" when used, since it could stand for residual sugars, reducing sugars, or reducing substances, which have different meanings (1), define residual sugar as the sum of glucose, fructose and sucrose expressed as $\mathrm{g} / \mathrm{L}$ of wine (2), use methods that are specific for wine sugars, rather than non-specific methods that test for reducing substances, to avoid erroneously high results (3), avoid reporting sugar alcohols, such as glycerol, as a sugar (4), avoid testing for sugars not expected in wine, such as maltose and lactose (5).
\end{abstract}

\section{Introduction}

The Tbilisi Principles adopted by the World Wine Trade Group (WWTG) in 2014 (and a similar set of Principles endorsed by FIVS) provide guidance on reducing barriers to wine trade and recommend regulatory approaches to reduce unnecessary obstacles arising in part due to variations in scientific terminology and analytical parameters used in wine analyses. One outcome at the 2015 International Wine Technical Summit (IWTS) [previously known as the International Wine Technical Forum] which includes various government and wine industry technical experts, was the development of technical working groups tasked with demonstrating the practical implementation of the Tbilisi Principles in wine trade facilitation. This paper is the second product of the working group that is performing this activity in relation to Tbilisi Principle \#06:

"Governments should adopt a common way of expressing analytical results in their rules, regulations, and requirements, where this is done in relation to a single wine constituent".

\section{Background}

Laboratory analyses of foods play an important role in ensuring the quality and safety of a food product such as wine. Laboratories in wine trading economies, however, frequently use different methods of analysis, reporting units and terminology to express the same analytical parameter.
Through dialogue among IWTS participants in past fora, one area of concern revealed problems in reporting of sugar in wine due to differences in sugar testing. For example, an importing economy may set limits for wine quality dependent on sugar concentration but tests for the wine sugar using a non-specific method, while the export economy may have used a different test method to certify compliance, or vice-versa.

As an illustration of how different test methods may provide varying results due to non-specificity of a test method, results for reducing sugars (non-specific) and Glucose + Fructose (specific) tested in the 2015 AsiaPacific Economic Cooperation (APEC) Wine Regulatory Forum (WRF) Ring Test [1] are compared with proficiency test results among participants in the Inter-winery Analysis Group (IWAG) and are provided below (Tables 1 and 2).

The results from the APEC WRF Ring Test provided above, combined with varying interpretation on nomenclature for various classes of sugars, test specificity, and differences in expressing sugar in wine as revealed in IWTS discussions, have led this Work Group to address the need for a harmonized system of expression for sugars methodology and terminology in wine.

\subsection{Definition of sugar terminology}

The following general definitions of sugar classes with respect to wine are provided below:

Reducing Sugar: Sugar with an aldehyde or keto-group (for example glucose, fructose and the pentoses, such as arabinose). The International Organisation of Vine and 
Table 1. Red Wine.

\begin{tabular}{|c|c|c|c|c|c|c|c|c|}
\hline Analyte & $\begin{array}{c}N \\
\text { (APEC) }\end{array}$ & $\begin{array}{c}\text { APEC } \\
\text { Mean }(\mathrm{g} / \mathrm{L})\end{array}$ & $\begin{array}{c}\text { APEC } \\
\text { StDev }\end{array}$ & $\begin{array}{c}\text { APEC } \\
\% \mathrm{CV}\end{array}$ & $\begin{array}{c}N \\
(\mathrm{IWAG})\end{array}$ & $\begin{array}{c}\text { IWAG } \\
\text { Mean }(\mathrm{g} / \mathrm{L})\end{array}$ & $\begin{array}{c}\text { IWAG } \\
\text { StDev }\end{array}$ & $\begin{array}{c}\text { IWAG } \\
\% \mathrm{CV}\end{array}$ \\
\hline Reducing Sugars & 12 & 4.51 & 1.39 & 29 & 42 & 4.34 & 0.8 & 18 \\
\hline Glucose + Fructose & 10 & 2.24 & 0.53 & 24 & 110 & 2.3 & 0.41 & 18 \\
\hline
\end{tabular}

Table 2. White Wine

\begin{tabular}{|c|c|c|c|c|c|c|c|c|}
\hline Analyte & $\begin{array}{c}N \\
(\text { APEC) }\end{array}$ & $\begin{array}{c}\text { APEC } \\
\text { Mean }(\mathrm{g} / \mathrm{L})\end{array}$ & $\begin{array}{c}\text { APEC } \\
\text { StDev }\end{array}$ & $\begin{array}{c}\text { APEC } \\
\% \mathrm{CV}\end{array}$ & $\begin{array}{c}N \\
(\mathrm{IWAG})\end{array}$ & $\begin{array}{c}\text { IWAG } \\
\text { Mean }(\mathrm{g} / \mathrm{L})\end{array}$ & $\begin{array}{c}\text { IWAG } \\
\text { StDev }\end{array}$ & $\begin{array}{c}\text { IWAG } \\
\% \mathrm{CV}\end{array}$ \\
\hline Reducing Sugars & 11 & 2.23 & 0.89 & 40 & 44 & 2.12 & 0.46 & 22 \\
\hline Glucose + Fructose & 10 & 0.95 & 0.16 & 17 & 110 & 0.92 & 0.23 & 25 \\
\hline
\end{tabular}

Table 3. Sugars by Method Comparison.

\begin{tabular}{|l|c|c|c|c|c|}
\hline Technology & Fructose & Glucose & Sucrose & Pentoses & Non-Sugar Reducing Substances \\
\hline HPLC-General & Yes & Yes & Yes & If tested & No \\
\hline HPLC- AOAC 2013.12 (Calculated as glucose) & Yes & Yes & Yes & No & No \\
\hline HPLC-OIV & Yes & Yes & Yes & No & No \\
\hline Enzymatic (Calculated as glucose) & Yes & Yes & No* & No & Yes \\
\hline Lane-Eynon/Reducing sugar & Yes & Yes & No** & Yes & Yes \\
\hline Rebelein (Gold Coast) /Reducing sugar & Yes & Yes & No** & Yes & No \\
\hline FTIR & Yes & Yes & Yes & No & \\
\hline
\end{tabular}

*Requires additional enzyme to hydrolyze into fructose-glucose ** if subjected to acid hydrolysis.

Wine (OIV) refers to the terms "reducing sugar", "residual sugar" and "inverted sugar" as glucose plus fructose in wine matrices.

- Does not include sucrose

- Should not be confused with reducing substances.

Residual Sugar: All fermentable sugars including sucrose

Reducing Substance: Includes glucose and fructose, plus oligosaccharides, and other reducing matter (such as tannin and polyphenols)

Non-fermentable Carbohydrates: These include pentoses, polysaccharides, (and pectins, tannins, pigments, all of which may interact with carbohydrates to form complexes [2,3].

Note that the first three definitions above are all abbreviated "RS" although they represent different meanings. The term residual sugar with reference to wine is understood to mean the sum of fermentable sugars: glucose, fructose (reducing sugars) and the non-reducing sugar, sucrose [4].

\subsection{Typical sugar composition in wine}

Sugar composition in Vitis vinifera grape varieties consist mainly of glucose and fructose with minor amounts of sucrose and pentoses [5]. A breakdown of typical sugar composition in grape must is given below [6]

- Glucose- $47.6 \%$

- Fructose-47.6\%

- Sucrose-3.1\%

- Pentoses- $1.1 \%$.

Glucose, fructose, and sucrose are the major components in wine sugar, totaling over $98 \%$ of wine sugar fraction. The sucrose in wine will hydrolyze to 1 molecule fructose and 1 molecule glucose at wine $\mathrm{pH}$. The other sugars present (pentoses) are at such a low level post fermentation that they are not of particular significance, having little or no impact on sweetness or wine stability.

\subsection{Methods of analysis}

Several methods of analyses for sugar in wine exist. Table 3 provides an overview of some common technologies and methods used when testing wine sugar in a regulatory environment. Note that methods that measure "reducing sugars" also measure reducing substances, resulting in erroneously high results as demonstrated earlier, in Tables 1 and 2 from the 2015 APEC WRF Ring Test and IWAG proficiency test results.

Reducing sugar methods depend on the ability of sugars to reduce copper (II) ions in solution; the disadvantage is that other reducing substances present in the wine (for example aldehydes, ketones, tannins and polyphenols) will also react with copper and give an erroneously high sugar value. As demonstrated in the APEC WRF Ring Test and the IWAG proficiency test results, reducing substances may overestimate wine sugar results by as much as 1-2 grams per liter (1-2 g/L). In a regulatory environment where a dry wine refers to wine with sugar of less than $4 \mathrm{~g} / \mathrm{L}$, overestimating sugars by 1-2 g/L may mean noncompliance.

The bias observed in reducing sugar methods where results are used for regulatory purposes may result in a wine being unnecessarily deemed unfit for entry.

Additionally, reducing sugar methods are known to be technique dependent, with results varying between laboratories and sometimes, analysts within the same laboratory. The high percent coefficient of variation (\% CV) demonstrated in the white wine 2015 APEC WRF Ring Test results for reducing sugar compared with methods testing for Glucose + Fructose (see Table 1 above) illustrates the variability of this method. Note that the method for reducing sugars gives coefficients of variation that are approximately double that for Glucose + Fructose (see Tables 1 and 2 above) illustrating the importance of using harmonized testing for wine sugar when used for compliance purposes in wine trade. 
Another concern in using reducing sugar methods to determine wine sugar is its use when calculating sugarfree extract. Testing for sugar-free extract is required by some importing economies and has been known to create an obstacle when the tested wine does not comply with an economy's requirement for sugar-free extract content. An erroneously high sugar result due to measurement of reducing substances will result in a negative bias in reporting sugar-free extract. Where an importing economy's wine regulations require a defined range of sugar-free extract, a sugar-free extract value below the defined range due to inaccurate sugar testing may cause unnecessary obstruction to wine trade.

Given the arguments presented against the use of methods that test for reducing substances, this Work Group proposes that economies regulating sugar in wine avoid methods that may include reducing substances. Methods that specifically measure for fructose and glucose (enzymatic, HPLC, FTIR, etc.), are encouraged when reporting sugar in wine.

\subsection{Testing and reporting of other wine components as typical wine sugar}

Through further discussions with IWTS attendees, this Work Group was made aware that some economies may report other wine constituents (for example glycerol) as part of the sugar fraction in wine. Although glycerol is a wine constituent and is easily quantified by HPLC techniques when testing for fructose, glucose and sucrose, it is a sugar alcohol and not defined as a sugar. While glycerol and other sugar alcohols present in the wine do influence how a wine tastes, sugar alcohols present a different class of compounds from a chemical and caloric perspective. Inclusion of glycerol as a sugar compound will erroneously result in high total sugar content in the wine, which as described above, will then result in an erroneously low sugar-free extract number.

Some economies revealed that in addition to testing wine for glucose, fructose and sucrose, they also tested wine for maltose and lactose. While technology is available to test for these components, the Work Group cautions against testing and reporting of maltose or lactose, as they are not typical wine components. Misidentification of maltose and lactose would result in a false positive for a component not normally found in traditional wine, give a high total sugar value and thus erroneous sugar result for the wine. Since glucose, fructose and sucrose are the major sugar components contributing to wine sweetness, the Work Group suggests limiting testing to these components.

\section{Conclusions and recommendations for future work}

This Work Group has carefully considered the complexity of analysing and reporting for sugar in wine. Based on the arguments presented in this technical brief, the following best practices are proposed to reduce technical barriers arising through requirements for sugar testing in wine:

1. Clarify the meaning of the abbreviation "RS" when used, since it could stand for residual sugars, reducing sugars, or reducing substances, which have different meanings.

2. Define residual sugar as the sum of glucose, fructose and sucrose expressed as $\mathrm{g} / \mathrm{L}$ of wine.

3. Use methods that are specific for wine sugars, rather than non-specific methods that test for reducing substances, to avoid erroneously high results.

4. Avoid reporting sugar alcohols, such as glycerol, as a sugar.

5. Avoid testing for sugars not expected in wine, such as maltose and lactose.

\section{References}

[1] E. Wilkes, AWRI. Report for APEC Wine Regulatory Forum Ring Test (2015)

[2] A.E. Hagerman, Hydrolyzable Tannin Structural Chemistry (2010)

[3] B. Zoecklein, K.C. Fugelsang, B. Gump, F.S. Nury, Wine Anal. Prod. (1995)

[4] M.A. Amerine, H.W. Berg, R.E. Kunkee, C.S. Ough, V.L. Singleton, \& A.D. Webb, The Technology of Wine Making, $4^{\text {th }}$ Ed. (1980)

[5] M.A. Amerine, \& C.S. Ough, Methods for Analysis of Musts \& Wines (1980)

[6] Y. Margalit, Concepts in Wine Chemistry $2^{\text {nd }}$ Ed. (2004) 